\title{
The Consequences of Nutrition Hazards: A Literature Review
}

\author{
Le T. Trang, Nguyen T. Huong, Nguyen D. Khoi, Hoang T. T. Huong, Nguyen K. Hang, Le Kien
}

\begin{abstract}
A better understanding of the factors that mitigate the consequences of nutrition-related hazards and encourage resilience is required to prevent against or improve poor development outcomes. This study included a review of the literature. Dietary adequacy is essential for growth and development, but current data suggests that nutrition supplements alone is insufficient to generate resilience to defend against, alleviate, and recover from nutritional stressors, as well as to promote healthy development. It is vital to combine nutrition therapy with stimulation and responsive care. Combined nutrition and psychosocial stimulation treatments may be successful in promoting protective factors and mitigating risks for impaired cognitive, motor, social, and affective functioning, hence assisting children in adapting to adversity.
\end{abstract}

\section{Introduction}

Tình trạng thiếu hụt dinh dưỡng ở trẻ em sớm phổ biến ở các nước trung bình và thấp với hậu quả không chỉ liên quan đến khả năng sống sót và tăng trưởng kém mà còn dẫn đến kết quả phát triển kém. Trẻ em ở các cộng đồng khó khăn phải đối mặt với nhiều nguy cơ thiếu hụt dinh dưỡng, tuy nhiên một số trẻ em có thể ít nhạy cảm hơn hoặc có thể phục hồi nhanh hơn do suy dinh dưỡng. Cần hiểu rõ hơn về các yếu tố giúp kiểm soát tác động của các rủi ro liên quan đến dinh dưỡng và thúc đẩy khả năng phục hồi để bảo vệ chống lại hoặc cải thiện các kết quả kém phát triển.

Một đánh giá tài liệu được thực hiện từ tháng 8 đến tháng 12 năm 2019 và cập nhật vào tháng 8 năm 2020. Các tìm kiếm từ khóa chính sử dụng các thuật ngữ Dinh dưỡng, Suy dinh dưỡng, Phát 
triển Trẻ em, Chăm sóc Đáp ứng, Kích thích, Các Quốc gia Thu nhập Trung bình và Thấp và Khả năng phục hồi được thực hiện bằng PubMed và Psychinfo.

Chế độ ăn uống đầy đủ là rất quan trọng cho sự tăng trưởng và phát triển, nhưng bằng chứng hiện tại chỉ ra rằng chỉ bổ sung dinh dưỡng là không đủ để thúc đẩy khả năng phục hồi để bảo vệ chống lại, giảm thiểu và phục hồi khỏi các mối đe dọa dinh dưỡng và thúc đẩy sự phát triển lành mạnh. Sự kết hợp của các can thiệp dinh dưỡng với kích thích và chăm sóc đáp ứng là cần thiết. Các phương pháp tiếp cận dinh dưỡng kết hợp và kích thích tâm lý xã hội có thể phối hợp hiệu quả với nhau để thúc đẩy các yếu tố bảo vệ và giảm thiểu rủi ro đối với chức năng nhận thức, vận động, xã hội và tình cảm kém, giúp trẻ thích nghi trong thời gian nghịch cảnh. Tuy nhiên, kiến thức hiện có của chúng ta còn nhiều lỗ hổng để kết hợp các can thiệp dinh dưỡng và kích thích tâm lý xã hội một cách hiệu quả và thúc đẩy các can thiệp này trên quy mô lớn.

Nghiên cứu cần giải quyết các rào cản ở cấp độ gia đình, cộng đồng, chương trình và chính sách đã ngăn cản việc tiếp nhận các chiến lược can thiệp dinh dưỡng và tâm lý xã hội kết hợp. Cần có các cuộc điều tra sâu hơn về cách cung cấp hỗ trợ cho người chăm sóc, cho phép họ thực hiện chăm sóc thích hợp cho việc cho ăn và kích thích. Cuối cùng, tác động của các can thiệp kết hợp đối với các con đường chăm sóc và hòa giải viên bảo vệ thúc đẩy khả năng phục hồi cần được hiểu rõ hơn để xác định các lĩnh vực trọng tâm cho nội dung của chương trình can thiệp kết hợp giúp các gia đình ở những nơi có nguy cơ cao.

\section{Method}

Cơ sở dữ liệu Web of Science được tìm kiếm từ ngày 1 tháng 1 năm 1950, cho đến ngày tìm kiếm. Mục đích của bài đánh giá của chúng tôi là tổng hợp thông tin đã xuất bản trước đây về ảnh hưởng của các hiện tượng khí hậu. Khi các cụm từ tìm kiếm, các biến thể khác nhau của "Nutrition", 
"Malnutrition", "Child Development” đã được sử dụng. Các nghiên cứu bổ sung được phát hiện bằng cách tìm kiếm bằng tay. Để tiến hành sàng lọc và đánh giá toàn văn cho tất cả các bài báo, các tác giả đã sử dụng Covidence, một công cụ tổ chức điện tử để đánh giá có hệ thống. Dân số nghiên cứu, vị trí và mức độ phơi nhiễm của dân số nghiên cứu đều được tính đến.

Nguy cơ sai lệch được đánh giá ở các mức kết quả nghiên cứu cho mỗi nghiên cứu duy nhất dựa trên nguồn dữ liệu, dân số nghiên cứu, quy trình lấy mẫu, phương pháp thu thập và phân tích dữ liệu, và bất kỳ đặc điểm cụ thể nào của dân số. Các nghiên cứu có phương pháp luận bị nghi ngờ hoặc bị lỗi đã bị loại trừ. Từ các nghiên cứu đáp ứng các tiêu chí bao gồm, dữ liệu về khoảng thời gian, quốc gia nghiên cứu và tiểu vùng, xung đột được xác định, thiết kế nghiên cứu, dân số tham khảo, loại phơi nhiễm, kết quả sức khỏe, khả năng tiếp cận các nhu cầu cơ bản, tỷ lệ tử vong và mối liên quan giữa phơi nhiễm và kết quả đã được trích xuất vào một biểu mẫu trích xuất dữ liệu. Nếu có sẵn, dữ liệu về các yếu tố bảo vệ và giảm thiểu đối với kết quả sức khỏe trẻ em đã được tóm tắt. Khi phát hiện thiếu dữ liệu, các tác giả đã được liên hệ trong thời gian sớm nhất.

\section{Results and Discussion}

Bhandari và cộng sự. (2001) thực hiện một nghiên cứu được thiết kế để xác định xem việc cung cấp một lượng lớn thực phẩm bổ sung vi chất dinh dưỡng được hỗ trợ bởi tư vấn hoặc tư vấn dinh dưỡng đơn thuần sẽ cải thiện đáng kể sự tăng trưởng thể chất từ 4 đến 12 tháng tuổi. Trong một thử nghiệm có đối chứng, 418 trẻ 4 tháng tuổi được phân ngẫu nhiên vào một trong bốn nhóm và theo dõi cho đến khi trẻ 12 tháng tuổi. Nhóm đầu tiên được tư vấn dinh dưỡng và ngũ cốc lợi sữa; riêng nhóm thứ hai tư vấn dinh dưỡng hàng tháng. Để kiểm soát hiệu quả của việc thăm khám tại nhà hai lần một tuần để phát hiện bệnh tật, các cuộc thăm khám tương tự đã được thực hiện ở một trong các nhóm đối chứng (nhóm thăm khám); nhóm thứ tư không nhận được sự can thiệp nào. 
Năng lượng trung bình ăn vào từ các nguồn sữa không nguyên chất cao hơn ở nhóm bổ sung thực phẩm so với nhóm thăm khám là $1212 \mathrm{~kJ}$ ở tuần thứ $26(\mathrm{P}<0,001), 1739 \mathrm{~kJ}$ ở tuần thứ $38(\mathrm{P}$ $<0,001)$ và $2257 \mathrm{~kJ}$ ở tuần thứ $52(\mathrm{P}<0,001)$. Nhóm trẻ được bổ sung thực phẩm tăng cân hơn 250 g (khoảng tin cậy 95\%: 20-480 g) so với nhóm thăm khám. Sự khác biệt về chiều dài gia tăng trung bình trong quá trình nghiên cứu là $0,4 \mathrm{~cm}$ (khoảng tin cậy $95 \%$ : $-0,1-0,9 \mathrm{~cm}$ ). Nhóm tư vấn dinh dưỡng có năng lượng hấp thụ cao hơn dao động từ 280 đến 752 kJ ở các độ tuổi khác nhau (P <0,05 ở mọi lứa tuổi) nhưng không có lợi ích đáng kể về sự gia tăng cân nặng và chiều dài. Cần xác định các phương pháp để nâng cao tác động của các can thiệp này.

Grantham-McGregor và cộng sự. (1991) đã đánh giá tác động của việc bổ sung dinh dưỡng, có hoặc không có kích thích tâm lý xã hội, đối với trẻ em chậm lớn (thấp còi) từ 9-24 tháng tuổi ở Kingston, Jamaica. 129 trẻ em từ các khu dân cư nghèo được chia ngẫu nhiên vào bốn nhóm chỉ kiểm soát, chỉ bổ sung, chỉ kích thích, và bổ sung cộng với kích thích. Một nhóm trẻ không thấp còi phù hợp $(\mathrm{n}=32)$ cũng được bao gồm. Thực phẩm bổ sung bao gồm $1 \mathrm{~kg}$ sữa công thức mỗi tuần trong 2 năm và các buổi vui chơi kích thích hàng tuần tại nhà với một trợ lý sức khỏe cộng đồng. Sự phát triển của trẻ em (DQ) được đánh giá theo thang điểm phát triển trí tuệ của Griffiths. Ban đầu, $D Q$ của nhóm thấp còi thấp hơn của nhóm không thấp còi, và của nhóm đối chứng giảm trong quá trình nghiên cứu, làm tăng mức thâm hụt của họ. Kích thích và bổ sung có những tác động có lợi độc lập đáng kể đối với sự phát triển của trẻ em. Các ước tính về hiệu quả bổ sung nằm trong khoảng từ $2 \cdot 2$ (giới hạn tin cậy $95 \%-1 \cdot 4,5 \cdot 7$ ) đối với tỷ lệ phụ của bàn tay và mắt đến $12 \cdot 4(5 \cdot 4,19 \cdot 5)$ đối với tỷ lệ phụ của locomotor và đối với hiệu ứng kích thích từ $6 \cdot 4(2 \cdot 8,10 \cdot 0)$ cho tay và mắt đến $10 \cdot 3(3 \cdot 3,17 \cdot 3)$ cho locomotor. Các hiệu quả điều trị là phụ trợ, và các can thiệp kết hợp có hiệu quả hơn đáng kể so với một mình. 
Jain và cộng sự. (2002) đã tiến hành một đánh giá quan trọng của nhiều nghiên cứu đã cố gắng xác định xem việc cho con bú có ảnh hưởng có lợi đến trí tuệ hay không. Bằng cách tìm kiếm trên Medline và tài liệu tham khảo của các bài báo đã chọn, chúng tôi đã xác định được các ấn phẩm đánh giá mối liên quan giữa việc cho con bú và kết quả nhận thức. Sau đó, chúng tôi đánh giá và mô tả từng nghiên cứu theo 8 nguyên tắc của dịch tễ học lâm sàng: 1) thiết kế nghiên cứu, 2) đối tượng mục tiêu: trẻ đủ tháng có được nghiên cứu hay không, 3) cỡ mẫu, 4) thu thập dữ liệu cho ăn: liệu nghiên cứu có đáp ứng 4 tiêu chuẩn chất lượng hay không - định nghĩa phù hợp và thời gian cho con bú, thời điểm thích hợp và nguồn dữ liệu cho ăn, 5) kiểm soát độ nhạy cảm: liệu các nghiên cứu có kiểm soát tình trạng kinh tế xã hội và sự kích thích của trẻ hay không, 6) mù: liệu những người quan sát kết quả có mù với tình trạng bú hay không ,7) kết quả: liệu một bài kiểm tra cá nhân tiêu chuẩn về trí thông minh chung ở độ tuổi trên 2 tuổi có được sử dụng hay không, và 8 ) định dạng kết quả: liệu các nghiên cứu có báo cáo về quy mô tác động hay một số chiến lược khác để giải thích tác động lâm sàng của kết quả hay không. Chúng tôi đã xác định được 40 ấn phẩm thích hợp từ năm 1929 đến tháng 2 năm 2001. Hai mươi bảy (68\%) kết luận rằng việc cho con bú sẽ thúc đẩy trí thông minh. Tuy nhiên, nhiều nghiên cứu có những sai sót về phương pháp luận. Chỉ có 2 bài báo nghiên cứu trẻ đủ tháng và đáp ứng tất cả 4 tiêu chuẩn về dữ liệu nuôi dưỡng chất lượng cao, được kiểm soát 2 yếu tố gây nhiễu quan trọng, báo cáo mù mắt, sử dụng xét nghiệm thích hợp và cho phép người đọc giải thích ý nghĩa lâm sàng của các phát hiện với kích thước ảnh hưởng. Trong số 2 nghiên cứu này, 1 nghiên cứu kết luận rằng ảnh hưởng của việc nuôi con bằng sữa mẹ đối với trí tuệ là đáng kể, và nghiên cứu còn lại thì không.

Super et al. (1990) tiến hành một nghiên cứu trong đó 280 trẻ sơ sinh Colombia có nguy cơ suy dinh dưỡng được phân ngẫu nhiên vào 1 trong 4 nhóm thực nghiệm được hình thành bởi sự hiện diện / không có 2 biện pháp can thiệp: (1) bổ sung thực phẩm cho cả gia đình, từ giữa thai kỳ cho 
đến khi đứa trẻ mục tiêu là 3 tuổi, và (2) chương trình thăm khám tại nhà hai lần một tuần để thúc đẩy sự phát triển nhận thức, từ sơ sinh cho đến 3 tuổi. Tất cả các gia đình đều được chăm sóc y tế miễn phí và được nghiên cứu khả năng. Lúc 3 tuổi, trẻ được bổ sung thức ăn cao trung bình 2,6 cm và lớn hơn 642 gram so với nhóm chứng. Việc thăm khám và bổ sung tại nhà cùng nhau đã làm giảm số lượng trẻ em chậm phát triển nặng. 3 năm sau can thiệp (6 tuổi), hiệu quả bổ sung vẫn còn. Trẻ em trong tình trạng thăm khám tại nhà đã trở nên lớn hơn so với nhóm chứng, 1,7 cm và 448 gram. Ở độ tuổi này, hiệu quả tương tác để giảm thấp còi là đáng kể và sự phân bổ tổng thể của điểm số đã được cải thiện. Các kết quả khác cho thấy rằng những thay đổi trong hoạt động của gia đình cũng như các cơ chế sinh học là nguyên nhân dẫn đến mô hình kết quả quan sát được.

Waber và cộng sự (1981) đã nghiên cứu trẻ sinh ra trong các gia đình có nguy cơ suy dinh dưỡng từ đầu quý 3 của thai kỳ người mẹ cho đến khi trẻ được 3 tuổi để xác định ảnh hưởng của việc bổ sung dinh dưỡng và / hoặc chương trình giáo dục của bà mẹ đối với trẻ. phát triển nhận thức. Bốn trăm ba mươi ba gia đình được phân chia ngẫu nhiên thành sáu nhóm: nhóm A đóng vai trò là đối chứng; nhóm $\mathrm{B}$ được bổ sung từ 6 tháng tuổi đến 3 tuổi; nhóm $\mathrm{C}$ được bổ sung trong 3 tháng giữa thai kỳ và 6 tháng đầu đời của trẻ; và nhóm $\mathrm{D}$ nhận được phần bổ sung trong toàn bộ thời gian nghiên cứu. Ngoài ra, nhóm $\mathrm{A} 1$ đã được ghi danh vào chương trình giáo dục bà mẹ nhưng không được bổ sung dinh dưỡng và nhóm $\mathrm{B} 1$ nhận được cả hai phương pháp điều trị. Bài kiểm tra Griffiths về sự phát triển của trẻ sơ sinh được thực hiện khi trẻ 4, 6, 12, 18, 24 và 36 tháng tuổi, và thang điểm Corman-Escalona Einstein được thực hiện ở mỗi độ tuổi đến 18 tháng. Những trẻ được bổ sung thực phẩm có kết quả tốt hơn những trẻ không được bổ sung, đặc biệt là đối với các bài kiểm tra chủ yếu là vận động. Ảnh hưởng của bổ sung thực phẩm đối với hành vi dường như là đồng thời. Ngoài ra, hiệu quả điều trị ở trẻ em gái rõ rệt hơn so với trẻ em trai trong mẫu này. Mặc dù những biện pháp can thiệp này đã làm giảm khoảng cách về hiệu suất nhận thức giữa các tầng 
lớp kinh tế xã hội thấp hơn và thượng lưu, tuy nhiên, sự chênh lệch vẫn còn cho đến cuối nghiên cứu.

Villar và cộng sự. (1982) đã nghiên cứu tỷ lệ tương đối của sinh non ( $\leq 2.500$ gm, tuổi thai $<37$ tuần) và chậm phát triển trong tử cung-nhẹ cân (IUGR-LBW) ( $\leq 2.500 \mathrm{gm}$, tuổi thai $\geq 37$ tuần) trong tổng số trẻ sơ sinh có LBW ở 11 các vùng ở những vùng rừng rậm đã phát triển và 25 vùng đang phát triển nơi đã biết tuổi thai và cân nặng khi sinh. Ở các nước đang phát triển có mối tương quan thẳng hàng giữa tổng tỷ lệ mắc LBW và tỷ lệ mắc IUGR-LBW ( $\mathrm{r}=0,95 ; \mathrm{b}=0,98 ; \mathrm{p}<0,001)$; ngược lại, sinh non không liên quan đáng kể đến tổng tỷ lệ mắc LBW. Dữ liệu từ các quần thể đã phát triển cho thấy kết quả hoàn toàn ngược lại với những kết quả được mô tả cho các khu vực đang phát triển. Do đó, khi tỷ lệ mắc LBW cao hơn 10\%, hầu như chỉ do sự gia tăng IUGR-LBW ở trẻ sinh non, trong khi trẻ sinh non hầu như không thay đổi ( $5 \%$ đến $7 \%)$. Khi tỷ lệ mắc LBW dưới $10 \%$ (trung bình $=6 \%$ ), trẻ sinh non đại diện cho thành phần chính của LBW. Các yếu tố môi trường dễ bị thay đổi bởi các điều kiện kinh tế xã hội có thể là nguyên nhân dẫn đến những khác biệt quan sát được. 